\title{
CHEMPHYSCHEM
}

Accepted version of manuscript: https://doi.org/10.1002/cphc.201800735

\section{Ionic Liquids derived from proline: application as surfactants}

\author{
Verónica Fernández-Stefanuto ${ }^{[a]}$, Raquel Corchero ${ }^{[b]}$, Iria Rodríguez-Escontrela ${ }^{[b]}$, Ana Soto ${ }^{[b]}$, and \\ Emilia Tojo*[a]
}

\begin{abstract}
: lonic liquids derived from prolinium esters, previously described as fully green and stable, were found to decompose in the presence of water by ester hydrolysis. To avoid this problem, a new family of these biodegradable salts incorporating an alcohol instead of the ester group is proposed. From this family, two novel ionic liquids that incorporate prolinolium cation, [HOPro], and [DS] or [DBS] anion were selected. Both salts are liquid at room temperature a property not usually found in ionic surfactants, as well as chemically and thermally stable. Moreover, they are more effective in reducing the surface tension of water than the corresponding traditional surfactants in the form of sodium salts, being useful for applications related to their aggregation capacity. They were tested for surfactant enhanced oil recovery and an optimal formulation for reservoirs at high salinity and temperature, able to produce ultra-low interfacial tension, was found with [HOPro][DBS].
\end{abstract}

\section{Introduction}

Decades ago, lonic Liquids (ILs) started to attract a lot of attention due to their "green" properties. However, the scientific community immediately began to notice that this "green" character was solely due to their practically negligible vapor pressure, associated with an absence of air contamination. ILs are frequently rather toxic and often present limited biodegradability. ${ }^{[1]}$ Instead, the main advantage of ILs is that they can be functionalized in order to get a specific physical, chemical or biological property or even for a specific application. ${ }^{[2,3]}$ Thus, cations, anions, the length and shape of alkyl side-chains, and functional groups can be selected in order to obtain, for instance, a green (in the widest sense of the word) IL or a Surface Active Ionic Liquid (SAIL).

Amino acid ILs have been highlighted as "fully green" alternative solvents to traditional ILs having synthetic chemical components. ${ }^{[4]}$ Their use has been proposed as solvents or catalysts, ${ }^{[4]}$ for $\mathrm{CO}_{2}$ capture, ${ }^{[5]}$ and for the separation of the main compounds of lignocellulosic biomass. ${ }^{[6,7]}$ Moreover, as they have the general advantages of ILs but also possess better

[a] V. Fernández Stefanuto, Prof. E. Tojo Department of Organic Chemistry Universidade de Vigo

Marcosende, As Lagoas, 36210 Vigo (Spain)

*E-mail: etojo@uvigo.es

[b] R. Corchero, Dr. I. Rodríguez-Escontrela, Prof. A. Soto

Department of Chemical Engineering

Universidade de Santiago de Compostela

15782 Santiago de Compostela (Spain)

Supporting information for this article is given via a link at the end of the document. biocompatibility for enzyme molecules, their application in enzyme immobilization, enzymatic biocatalysis, and enzyme biosensor are very promising. ${ }^{[8]}$

SAILs show a wide number of applications that derive from the two fundamental properties of surface active agents in aqueous solution: adsorption at the surface or interface, and aggregation. Conventional ionic surfactants, being salts with melting points below $373.15 \mathrm{~K}$, have only rather recently been seen as ILs. Such is the case of dodecyl-dimethylbenzylammonium chloride, which is widely used as a bactericide. In fact, even solvents used for decades in the large-scale production are only recently considered as ILs able to produce a safe environment. ${ }^{[9]}$ The attention paid in recent decades to ILs is leading to the synthesis of new surfactants able to be used in applications where the choice of conventional surfactants is limited. Collins et al. ${ }^{[10]}$ were pioneering on presenting synthetic methods and applications of SAILs. Depending on the hydrophilic-lipophilic balance index, they cited some applications that include their use for the preparation of foams for mobility control, the dispersion of oil spills, as emulsifiers or wetting agents, as hydrophobic solvents, as lubricants or heat transfer agents in drilling fluids, as inhibitors of gas hydrates or corrosion in oil production, as recovery-enhancing additives in oil recovery, hydraulic fluids, milling or cutting fluids, phase transfer agents or drug delivery agents, and as chemical reaction media (e.g. for micellar catalysis). Besides the general advantages of ILs, the delocalized charges associated to the special head-groups of these compounds can also deliver special interfacial properties to the systems in which they are included. ${ }^{[11]}$

Trivedi et al. ${ }^{[12]}$ chose natural amino acids and sodium lauryl sulfate as precursors for amino acid ILs surfactant architectures. These authors synthesized biobased SAlLs with a superior surface activity and solvent miscibility for the first time. To achieve that aim, the esterification of the amino acids was carried out to decrease the melting point and to increase the biodegradability of the generated salts.

Perhaps one of the most promising applications of SAILs is their usage to overcome the current limitations of surfactant flooding Enhanced Oil Recovery (EOR). ${ }^{[13,14]}$ Obtaining a biobased SAIL to design an optimal formulation, stable in aqueous salt solutions and able to obtain ultra-low interfacial tensions, could mean a definitive advance in EOR with surfactants. Therefore, in this work, the limitations of the SAILs proposed by Trivedi et al. ${ }^{[12]}$ were studied and novel SAILs able to overcome these limitations were synthesized for the first time. The most stable SAILs were selected, characterized, and their capacity to be used in EOR was analyzed. 


\section{Results and Discussion}

\section{Synthesis}

Taking into account the promising properties previously shown for ILs derived from the iso-propyl and iso-butyl esters of (L)prolinium (1) and dodecylsulfate anion, ${ }^{[12]}$ the starting point of this work was the synthesis of similar structures introducing different alkyl chains in the ester group (Scheme 1). The alkyl chains selected were $n$-butyl to give the IL $\left[{ }^{n} \mathrm{C}_{4}\right.$ Pro] [DS] (6), isobutyl to give $\left[{ }^{i} \mathrm{C}_{4} \mathrm{Pro}\right][\mathrm{DS}](7), 2$-butyl-octyl to give $\left[\mathrm{C}_{4} \mathrm{C}_{8} \mathrm{Pro}\right][\mathrm{DS}]$ (8) and 2-decyl-tetradecyl to give $\left[\mathrm{C}_{10} \mathrm{C}_{14}\right][\mathrm{DS}]$ (9). Their synthesis was carried out in two steps. The first one involved the esterification of L-proline (1) by treatment with a suitable alcohol in the presence of thionyl chloride $\left(\mathrm{SOCl}_{2}\right)$ to obtain the corresponding esterified prolinium chlorides 2-5 with high yields. A later methatesis reaction with sodium dodecylsulfate gave the desired ILs 6-9. To our knowledge, all these salts except those derived from $\left[{ }^{i} \mathrm{C}_{4}\right.$ Pro] cation are described in this work for the first time. The structures of all synthesized ILs were confirmed by ${ }^{1} \mathrm{H}$ and ${ }^{13} \mathrm{C}$ NMR spectroscopy (see supporting information) as well as low and/or high MS spectrometry. The ILs with a short alkyl chain $\left[{ }^{n} \mathrm{C}_{4}\right.$ Pro][DS] $(6)$ and $\left[{ }^{i} \mathrm{C}_{4}\right.$ Pro] [DS] (7), were found to be water soluble, while those with long alkyl chains, $\left[\mathrm{C}_{4} \mathrm{C}_{8}\right.$ Pro] $[\mathrm{DS}](\mathbf{8})$ and $\left[\mathrm{C}_{10} \mathrm{C}_{14}\right.$ Pro][DS] (9), formed two phases when water was added.

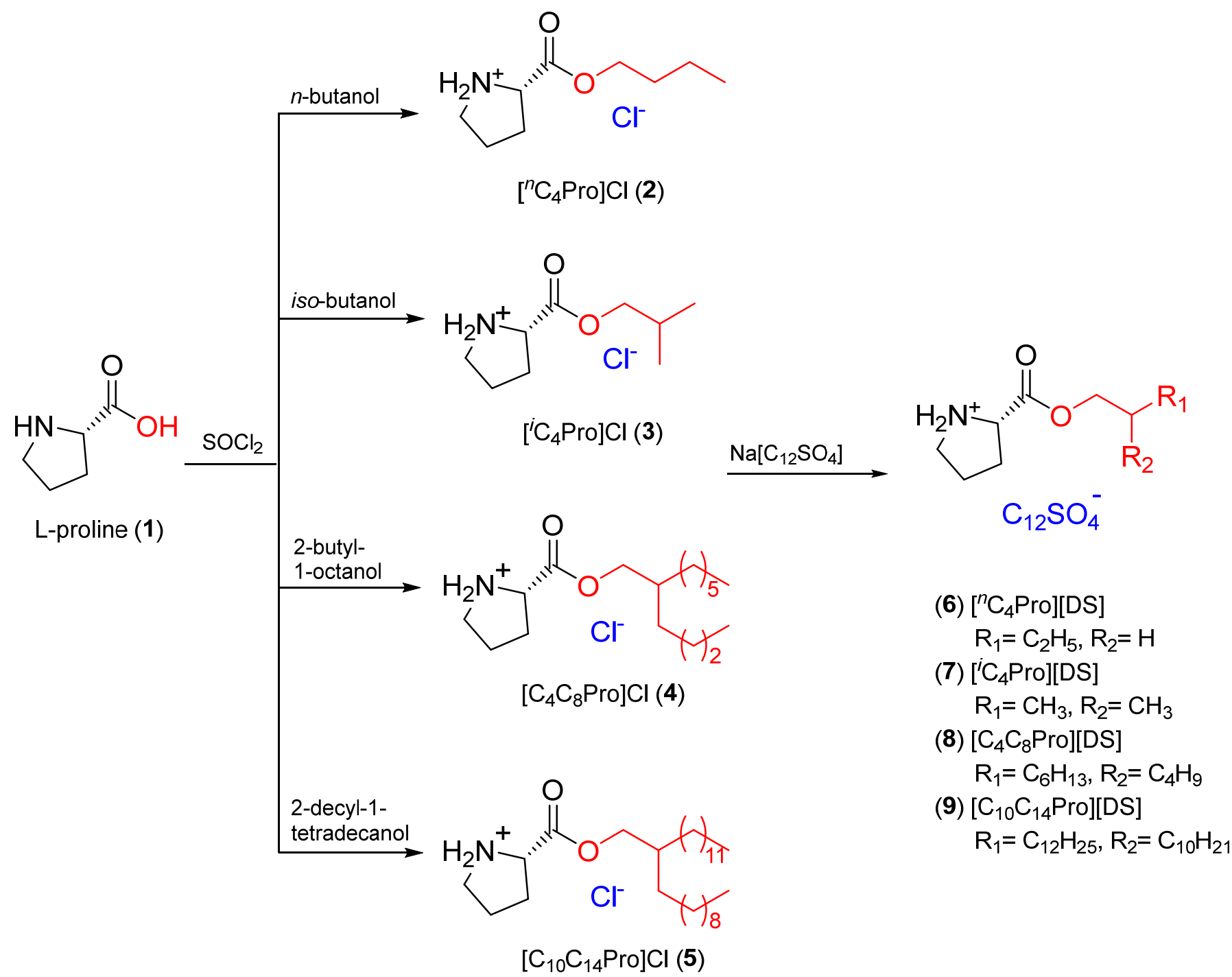


Although a previous report about ${ }^{i} \mathrm{C}_{4}$ Pro][DS] (7) showed a high thermal stability (onset temperature $553.15 \mathrm{~K}$ ), ${ }^{[12]}$ what is promising from the point of view of the thermal stability of this SAIL, in this work some decomposition was observed after several weeks when it was kept at room temperature in the presence of water. To go into more detail about the decomposition process, a water solution of the IL was heated for some days at 313.15 and at $373.15 \mathrm{~K}$. The analysis by ${ }^{1} \mathrm{H}$ NMR spectroscopy showed that when $\left[{ }^{i} \mathrm{C}_{4}\right.$ Pro][DS] (7) is heated in water, the ester group undergoes hydrolysis to give the corresponding prolinium hydroxide, dodecylsulfonic acid and isobutyl alcohol (Scheme 2). Liquid-liquid extraction with $\mathrm{CH}_{2} \mathrm{Cl}_{2}$ allowed the separation of dodecylsulfonic acid (organic phase) from the prolinium hydroxide (aqueous phase), which was confirmed by the ${ }^{1} \mathrm{H},{ }^{13} \mathrm{C}$ NMR and MS data of the isolated compounds (see Supporting Information). A similar problem of degradation was previously reported. ${ }^{[15]}$ As it is shown in Table 1, when the IL is heated at $313.15 \mathrm{~K}$ for 4 days or at $373.15 \mathrm{~K}$ for 1 day, the decomposition is only partial; but the decomposition is total after keeping the temperature at $373.15 \mathrm{~K}$ for 4 days.<smiles>CC(C)COC(=O)[C@@H]1CCC[NH2+]1</smiles>

Scheme 2. Decomposition of ['C ${ }_{4}$ Pro][DS] (7) by hydrolysis.

Table 1. Decomposition of $\left[{ }^{i} \mathrm{C}_{4}\right.$ Pro][DS] (7) and ['C $\mathrm{C}_{4}$ Pro][DBS] (10) when heating in water.

\begin{tabular}{|c|c|c|c|}
\hline IL & Temperature $(\mathrm{K})$ & Days & Decomposition \\
\hline$\left[{ }^{[} \mathrm{C}_{4}\right.$ Pro][DS] (7) & 313.15 & 1 & No \\
\hline$\left[{ }^{[} \mathrm{C}_{4}\right.$ Pro][DS] (7) & 313.15 & 4 & Partial \\
\hline$\left[{ }^{[} \mathrm{C}_{4}\right.$ Pro][DS] (7) & 373.15 & 1 & Partial \\
\hline$\left[\mathrm{C}_{4}\right.$ Pro][DS] (7) & 373.15 & 4 & Complete \\
\hline$\left[\mathrm{C}_{4} \mathrm{Pro}\right][\mathrm{DBS}](10)$ & 373.15 & 5 & Partial \\
\hline [HOPro][DS] (13) & 313.15 & 4 & No \\
\hline [HOPro][DS] (13) & 373.15 & 4 & Partial \\
\hline [HOPro][DBS] (14) & 373.15 & 5 & No \\
\hline
\end{tabular}

Knowing the high stability of ILs derived from dodecylbenzenesulfonate anion [DBS], ${ }^{[16]}$ the IL $\left[{ }^{[} C_{4}\right.$ Pro] $[D B S](10)$ was synthesized by treatment of the corresponding chloride $\left[{ }^{i} \mathrm{C}_{4} \mathrm{Pro}\right] \mathrm{Cl}$ (3) with sodium dodecyl benzenesulfonate (Scheme 3 ). Its structure, no previously reported in literature, was confirmed by ${ }^{1} \mathrm{H}$ and ${ }^{13} \mathrm{C}$ NMR spectroscopy as well as HRMS spectrometry (see Supporting Information). This IL was found to be also soluble in water. However, the analysis of its stability when heating in water showed that although it is more stable than the [DS] analogue (7), there is a partial decomposition after heating at $373.15 \mathrm{~K}$ for 5 days (Table 1).

In order to avoid the ester hydrolysis, the synthesis of ILS derived from (L)-prolinol (11) was then approached (Scheme 4). Starting from (L)-proline (1), it was first reduced by treatment with $\mathrm{LiAlH}_{4}$ to afford (L)-prolinol (11), that after protonation with an aqueous solution of $\mathrm{HCl} 2 \mathrm{M}$ gave (S)-(+)-2-(hydroxymethyl) pirrolidinium chloride [HOPro] $\mathrm{Cl}$ (12).<smiles>CC(C)COC(=O)[C@@H]1CCC[NH2+]1</smiles>

$\left[{ }^{i} \mathrm{C}_{4} \mathrm{Pro}\right][\mathrm{Cl}](3)$<smiles>CC(C)COC(=O)[C@@H]1CCC[NH2+]1</smiles><smiles>CC(C)(C)c1ccc(S(=O)(=O)O)cc1</smiles>

$\left[{ }^{i} \mathrm{C}_{4}\right.$ Pro][DBS] (10) 
The anion exchange of [HOPro]Cl (12) by reaction with the suitable sodium salt (sodium dodecylsulfate $\mathrm{Na}[\mathrm{DS}]$ or sodium dodecyl benzenesulfonate $\mathrm{Na}[\mathrm{DBS}]$ ) allowed obtaining of (S)(+)-prolinolium dodecylsulfate [HOPro][DS] (13) and (S)-(+)-2prolinolium dodecylbenzene sulfonate [HOPro][DBS] (14). Their structures, no previously described, were confirmed by ${ }^{1} \mathrm{H}$ and ${ }^{13} \mathrm{C}$ NMR spectroscopy (see Supporting Information) as well as high resolution MS spectrometry. As expected, no hydrolysis of [HOPro] cation was observed in any of the two ILs, even after heating. Only a partial degradation of [DS] anion in [HOPro][DS] (13) was observed after heating for 4 days at $373.17 \mathrm{~K}$ (Table 1), due to the equilibrium that is produced between this anion and the corresponding dodecylsulfonic acid in aqueous solutions (see Supporting information).<smiles>O=C(O)[C@H]1CCCN1</smiles><smiles>C1CCNC1</smiles>

(L)-proline (1)<smiles>OC[C@@H]1CCC[NH2+]1</smiles>

[HOPro][Cl] (12)<smiles>CC(C)(CO)CC(C)(C)CS(=O)(=O)O</smiles>

[HOPro][DS] (13)<smiles>CC(C)(C)c1ccc(S(=O)(=O)[O-])cc1</smiles>

[HOPro][DBS] (14)

Scheme 4. Synthetic procedure applied to prepare ILs derived from (L)-prolinol (11).

\section{Thermal properties}

Due to their stability in aqueous solutions, [HOPro][DS] (13) and [HOPro][DBS] (14) were the most interesting alternatives for applications where water is involved. DSC analyses (Figure 1) were carried out to identify the phase transitions for both ILs. The heating/cooling cycles ranged between 190 and $370 \mathrm{~K}$, at rates of $5 \mathrm{~K} \cdot \mathrm{min}-1$. In the case of [HOPro][DS] (13), one endothermic peak was observed in the heating ramp at $305 \mathrm{~K}$. The onset temperature of the peak, $295 \mathrm{~K}$, was considered as the melting temperature of the IL. For the SAIL with the [DBS] anion no peaks were observed. However, there is a step in the heat, which is indicative of a glass transition temperature that was determined as the inflexion point of the step in the DSC curve. A temperature of $201 \mathrm{~K}$ was obtained.

Decomposition temperatures were determined by TGA. In the weight vs. temperature plots, a double-step decomposition was observed, with a $5 \%$ onset decomposition temperature (onset temperature for a $5 \%$ weight loss of the original mass) of $454 \mathrm{~K}$ for the [HOPro][DS] (13) and $564 \mathrm{~K}$ for [HOPro][DBS] (14) (Figure 2). In the case of $\left[{ }^{i} \mathrm{C}_{4}\right.$ Pro][DS] a value of about $478 \mathrm{~K}$ was found ${ }^{[12]}$.
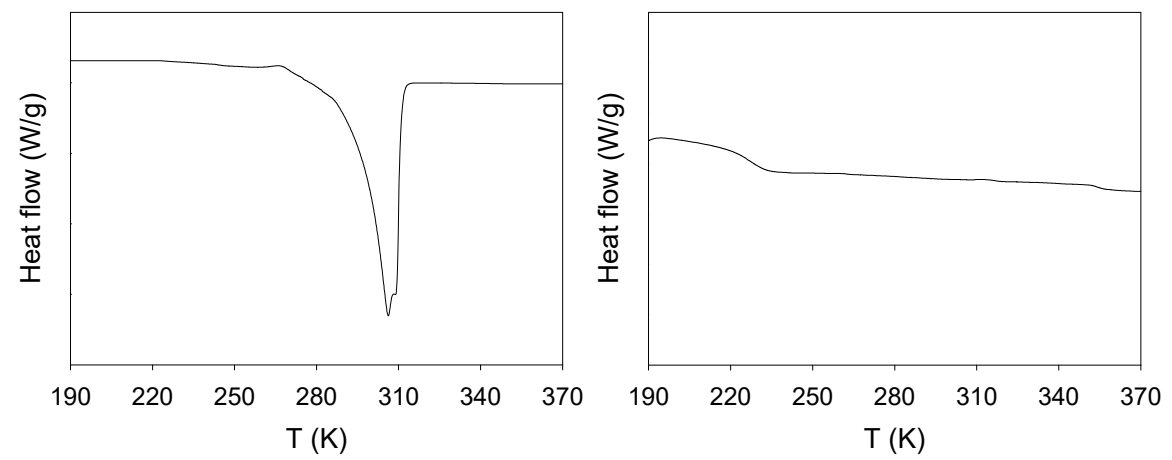

Figure 1. DSC thermograms of [HOPro][DS] (13) (left) and [HOPro][DBS] (14) (right). 

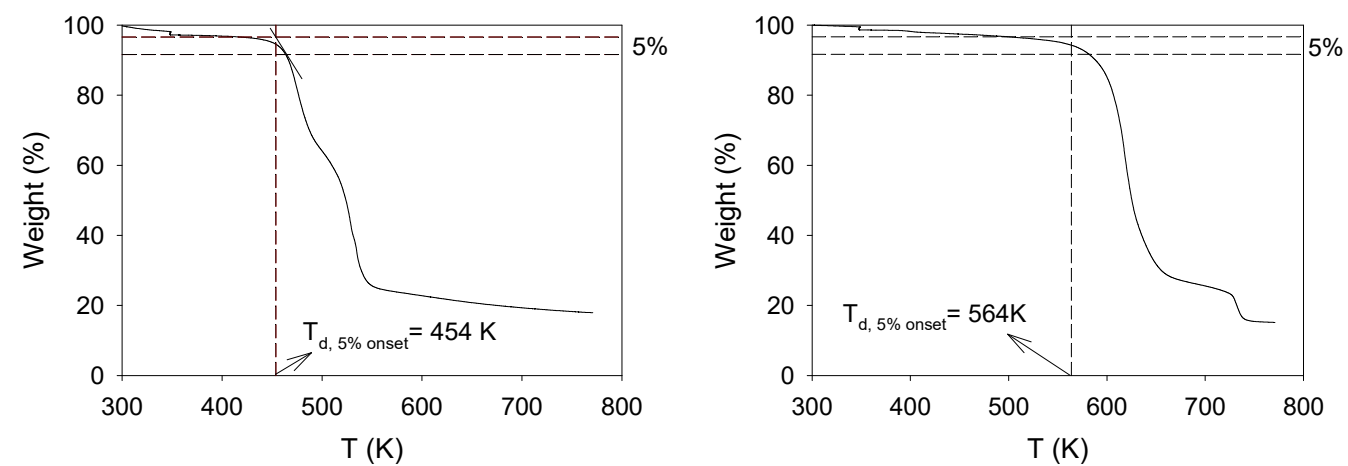

Figure 2. TGA thermograms of [HOPro][DS] (13) (left) and [HOPro][DBS] (14) (right). The TGA thermogram also shows the calculation of the 5\% onset decomposition temperature: the crossing of the tangent at the point of $5 \%$ weight loss with the stable weight of initial sample before the starting of decomposition.

\section{Aggregation behavior in aqueous solution}

Surface tension was used to check the surface active character of the studied ILs and to determine the critical micelle concentration $(\mathrm{cmc})$ in aqueous solution at $298.15 \mathrm{~K}$. Figure 3 shows the change in surface tension $(\gamma)$ as a function of the logarithm of the concentration in water of [HOPro][DS] (13) left) and [HOPro][DBS] (14) (right). Usually, surface tension decreases until a constant value of this property is achieved and the breakpoint is the $\mathrm{cmc}$. However, as it can be seen in Figure 3 (left), for [HOPro][DS] (13) a minimum in the surface tension was found before stabilisation of the property. This behavior is common with [DS] surfactants and it is widely accepted that the minimum is caused by the presence of the highly surface-active lauryl alcohol, due to the hydrolysis of the [DS] anion in aqueous solution. ${ }^{[17]}$ For this SAIL, and as is usual, the $c m c$ is defined as the concentration where the surface tension goes up and reaches the equilibrium value at increasing surfactant concentration. Values of $\mathrm{cmc}$ and the corresponding surface tension are given in Table 2 for both SAILS and their parent compounds (common surfactants with sodium cations). The $\mathrm{cmc}$ obtained for the SAILs is lower than for their sodium analogues: sodium dodecylsulfate ( $\mathrm{Na}[\mathrm{DS}])$ and sodium dodecylbenzenesulfonate (Na[DBS]). Comparing $\mathrm{cmc}$ of [HOPro][DS] (13) and [ ${ }^{i} \mathrm{C}_{4}$ Pro][DS] (7), the latter has a clearly lower value $\left(0.48 \mathrm{mM}^{[18]}\right)$. As Rao et al. ${ }^{[18]}$ indicated, more hydrophobic counterions normally lead to the reduction in $\mathrm{cmc}$. In this case [HOPro] cation is more hydrophilic due to the presence of the group $\mathrm{OH}$.
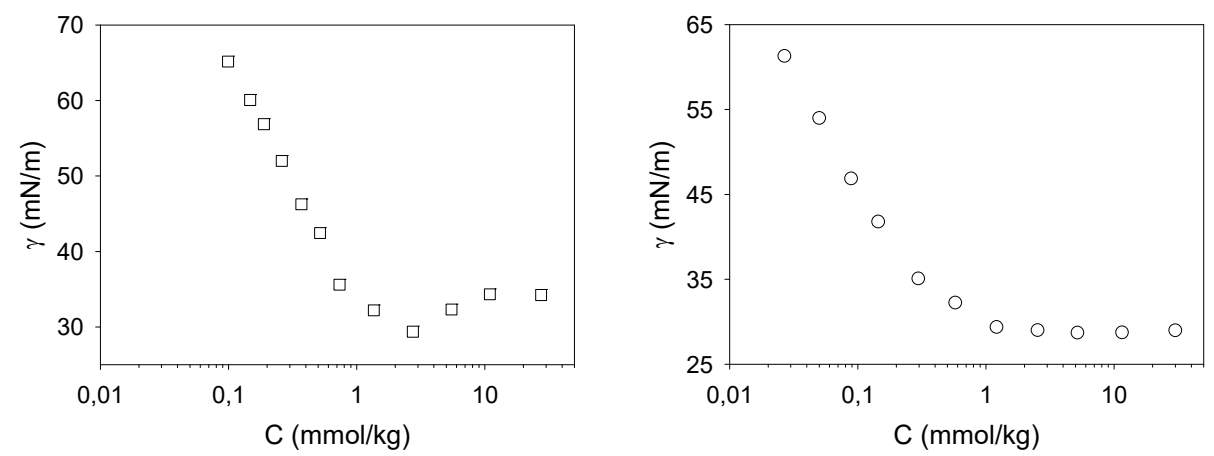

Figure 3. Surface tension as function of [HOPro][DS] (13) (squares, left) and [HOPro][DBS] (14) (circles, right) concentration in aqueous solution at 298.15 K.

The effectiveness of a surfactant to lower the surface tension of water can be evaluated by means of two parameters: $p C_{20}$ $\left(C_{20}\right.$ being the concentration required to reduce the surface tension of pure water by $20 \mathrm{mN} \cdot \mathrm{m}^{-1}$ ) and the surface pressure at cmc $\left(\Pi_{c m c}\right)$, the difference between surface tensions of pure water and the surfactant solution at the $\mathrm{cmc}$ :

$$
\begin{aligned}
& p C_{20}=-\log C_{20} \\
& \Pi_{c m c}=\gamma_{w a t e r}-\gamma_{c m c}
\end{aligned}
$$


Table 2. Parameters derived from surface tension data for [HOPro][DS] (13) and [HOPro][DBS] (14) SAILs and parent compounds at 298.15 K and atmospheric pressure.

\begin{tabular}{|c|c|c|c|c|c|c|}
\hline SAIL & $c m c(\mathrm{mM})$ & $\gamma_{c m c}(\mathrm{mN} / \mathrm{m})$ & $p C_{20}$ & $\Pi_{c m c}(\mathrm{mN} / \mathrm{m})$ & $\Gamma_{m}\left(\mu \mathrm{mol} / \mathrm{m}^{2}\right)$ & $a_{m}^{s}\left(\AA^{2}\right)$ \\
\hline [HOPro][DS] (13) & 2.74 & 29.30 & 3.59 & 42.70 & 1.72 & 96.4 \\
\hline $\mathrm{Na}[\mathrm{DS}]^{[19]}$ & 8.2 & 34.9 & 2.51 & 37.1 & 3.16 & 56 \\
\hline [HOPro][DBS] (14) & 1.25 & 28.75 & 4.26 & 43.25 & 0.29 & 570.14 \\
\hline $\mathrm{Na}[\mathrm{DBS}]^{[20]}$ & 2.90 & 38 & 2.6 & 34 & 2.3 & 74 \\
\hline
\end{tabular}

Results shown in Table 2 indicate that at the same concentration of surfactant, the SAILs produce a higher reduction of the surface tension than the corresponding parent compounds. Moreover, comparing the values for both SAILs, [HOPro][DBS] (14) is more efficient than the [DS] analogue.

The surface excess concentration of a surfactant $\left(\Gamma_{1}\right)$ and the area per molecule $\left(a_{1}^{s}\right)$ at the water-air interface can be determined on the basis of the adsorption isotherm using the Gibbs equation: ${ }^{[19]}$

$$
\begin{gathered}
\Gamma_{1}-\frac{10^{3}}{4.606 \cdot R \cdot T}\left(\frac{\partial \gamma}{\partial \log C_{1}}\right)_{T} \\
a_{1}^{S}=\frac{10^{26}}{N \Gamma_{1}}
\end{gathered}
$$

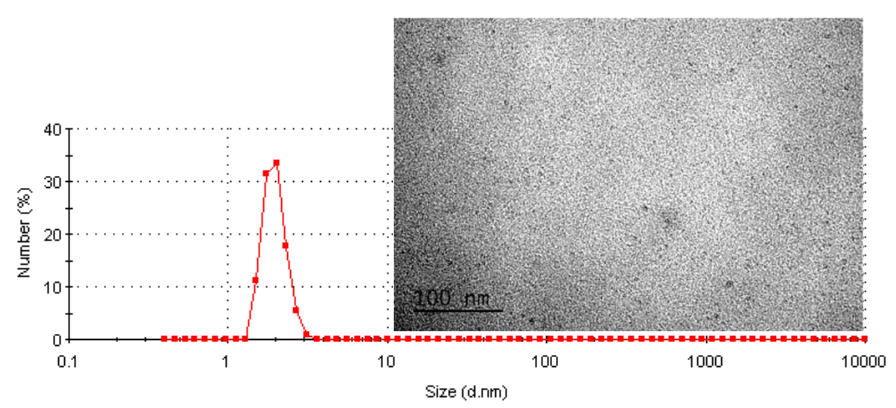

Figure 4. Size distribution of aggregates in aqueous solutions of [HOPro][DS] (13) (left) and [HOPro][DBS] (14) (right) by DLS and TEM.

The problem of the minimum found using surface tension to determine the $c m c$ of the SAIL [HOPro][DS] (13), can be solved using another physical property affected by the formation of micelles. For this reason, electrical conductivity measurements of aqueous solutions of prolinolium-based SAILs were also carried out to determine $\mathrm{cmc}$ values, expanding the study to analyze the influence of temperature. Figure 5 shows the conductivity aqueous solutions of the amino-acid SAILs at different concentrations and temperatures ranging from $288.15 \mathrm{~K}$ and $318.15 \mathrm{~K}$. The conventional method, using the intersection of
$C_{1}$ is the surfactant concentration ( $\left.\mathrm{mol} / \mathrm{kg}\right), \gamma$ the surface tension $(\mathrm{mN} / \mathrm{m}), N$ is the Avogadro constant. The derivative in equation (3) is obtained by fitting surface tension data up to the $\mathrm{cmc}$ to a second order polynomial. Table 2 presents values of the excess of surfactant concentration at the water-air interface $\left(\Gamma_{m}\right)$ and the area per molecule at the interface $\left(a_{m}^{s}\right)$, at surface saturation, for [HOPro][DS] (13), [HOPro][DBS] (14) and the corresponding parent compounds. From this Table, it can be seen that $\Gamma_{m}$ is lower and $a_{m}^{s}$ higher than values for the parent compounds. It means that the effectiveness of SAlLs adsorption at water-air interface is lower than traditional surfactants.

Aqueous solutions of [HOPro][DS] (13) and [HOPro][DBS] (14) were prepared with a concentration 20 times higher than the $\mathrm{cmc}$ and were analyzed at room temperature by means of Dynamic Light Scattering. Results are shown in Figure 4 showing a hydrodynamic radius of aggregates of 1-3 nm.

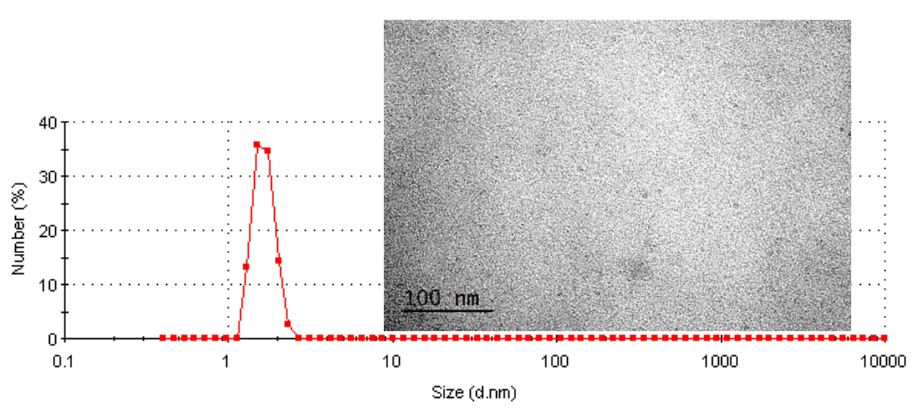

the two straight lines (obtained by linear regression of the experimental data at low and high concentrations) was applied to determine $\mathrm{cmc}$ values.

As shown in Figure 6, the $\mathrm{cmc}$ initially decreases and then increases with temperature, with the minimum in the 290-300 K range for [DS] anion and 305-315K for [DBS] anion. A similar behavior has been found with conventional surfactants and also with other proline-based SAILs. ${ }^{[18,19]}$ 

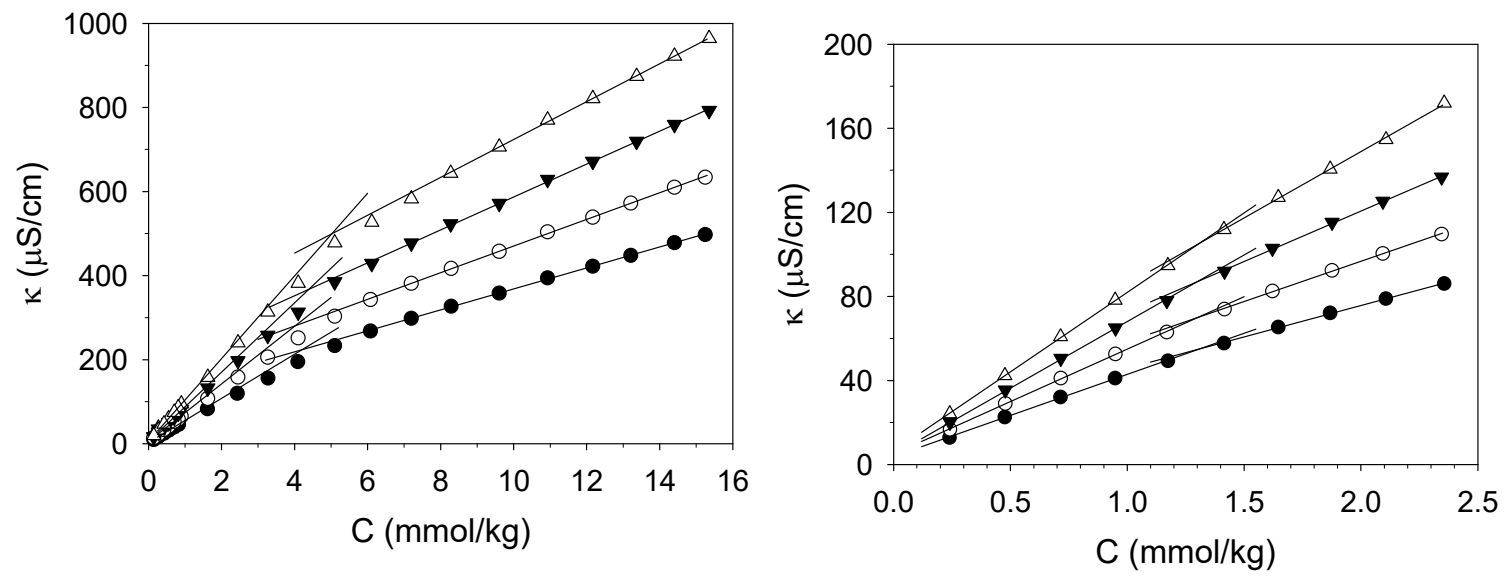

Figure 5. Conductivity as function of [HOPro][DS] (13) (left) or [HOPro][DBS] (14) (right) concentration in aqueous solution at different temperatures and atmospheric pressure. Closed circles: $288.15 \mathrm{~K}$, open circles: $298.15 \mathrm{~K}$, triangles down: $308.15 \mathrm{~K}$, triangles up: $318.15 \mathrm{~K}$.
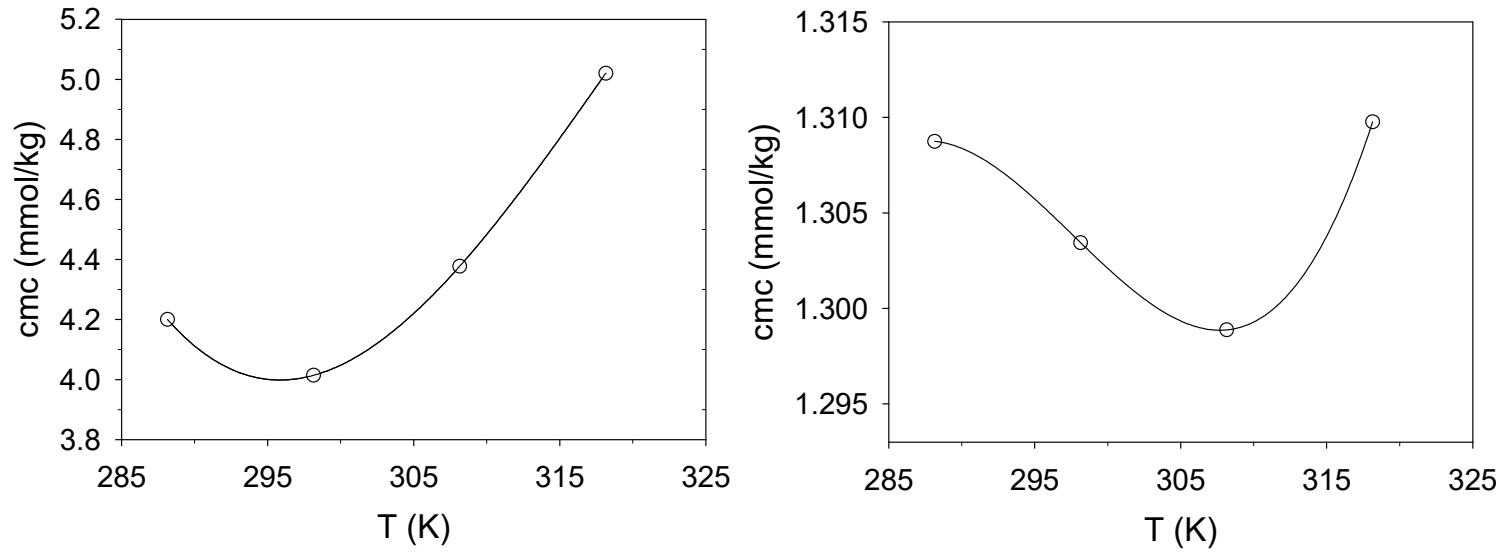

Figure 6. Plot of cmc as function of temperature for [HOPro][DS] (13) (left) [HOPro][DBS] (14) (right). Line drawn to guide the eye.

The tendency of surfactants to form micelles can be established on the basis of standard free energy of micellisation $\left(\Delta G_{\text {mic }}^{0}\right)$ :

$$
\Delta G_{m i c}^{0}=(1+\beta) R T \ln \left(X_{c m c}\right)
$$

being $X_{c m c}$ the mole fraction of SAIL at the $c m c$ and $\beta$ the degree of counterion binding. Basic equations can be applied to calculate standard enthalpy $\left(\Delta H_{m i c}^{0}\right)$ and entropy $\left(\Delta S_{m i c}^{0}\right)$ of micellisation:

$$
\Delta H_{m i c}^{0}=\frac{\partial\left(\frac{\mathrm{G}_{m i c}^{0}}{T}\right)}{\partial\left(\frac{1}{T}\right)}
$$

$$
\Delta \mathrm{S}_{\mathrm{mic}}^{0}=\frac{\Delta \mathrm{H}_{\mathrm{mic}}^{0}-\Delta \mathrm{G}_{\mathrm{mic}}^{0}}{\mathrm{~T}}
$$

Calculated values of $\beta, \Delta G_{m i c}^{0}, \Delta H_{m i c}^{0}$ and $\Delta S_{m i c}^{0}$ are given in Table 3 and Table 4 for [HOPro][DS] (13) and [HOPro][DBS] (14), respectively. The Gibbs energy of micellisation decreases with temperature. Therefore, the micellisation process becomes more spontaneous. The Gibbs energy of micellisation for SAILs is less negative (less spontaneous micellisation) than for parent compounds $\mathrm{Na}[\mathrm{DS}]$ and $\mathrm{Na}[\mathrm{DBS}] .{ }^{\left[{ }^{19]}\right.}$ Enthalpy of micellisation $\left(\Delta H_{m i c}^{0}\right)$ was positive at lower temperatures and negative at higher ones. The same behavior was found for conventional surfactants. ${ }^{[19,20]}$ Values of $T \Delta S_{m i c}^{0}$ indicate that the aggregation process is mainly entropy-driven at lower temperatures and mainly enthalpy driven at higher temperatures (see Tables 3 and 4). 
Table 3. Parameters derived from conductivity data for [HOPro][DS] (13) aqueous solution at different temperatures and atmospheric pressure.

\begin{tabular}{llllll}
\hline $\mathrm{T}(\mathrm{K})$ & $c m c(\mathrm{mmol} / \mathrm{kg})$ & $\beta$ & $\Delta \mathrm{G}^{\circ}{ }_{\text {mic }}(\mathrm{kJ} / \mathrm{mol})$ & $\left.\Delta H^{\circ}{ }_{\mathrm{mic}} \mathrm{KJ} / \mathrm{mol}\right)$ & $T \Delta S^{\circ}{ }_{\mathrm{mic}}(\mathrm{kJ} / \mathrm{mol})$ \\
\hline 288.15 & 4.20 & 0.53 & -34.62 & 10.59 & 45.21 \\
\hline 298.15 & 4.01 & 0.54 & -36.27 & -0.13 & 36.14 \\
\hline 308.15 & 4.38 & 0.53 & -36.87 & -10.16 & 26.71 \\
\hline 318.15 & 5.02 & 0.54 & -37.91 & -19.56 & 18.35 \\
\hline
\end{tabular}

Table 4. Parameters derived from conductivity data for [HOPro][DBS] (14) aqueous solution at different temperatures and atmospheric pressure.

\begin{tabular}{llllll}
\hline $\mathrm{T}(\mathrm{K})$ & $c m c(\mathrm{mmol} / \mathrm{kg})$ & $\beta$ & $\Delta \mathrm{G}^{\circ}{ }_{\text {mic }}(\mathrm{kJ} / \mathrm{mol})$ & $\left.\Delta \mathrm{H}^{\circ}{ }_{\text {mic }} \mathrm{KJ} / \mathrm{mol}\right)$ & 30.70 \\
\hline 288.15 & 1.309 & 0.23 & -31.46 & -2.36 & 30.16 \\
\hline 298.15 & 1.303 & 0.23 & -32.52 & -33.27 & 0.59 \\
\hline 308.15 & 1.299 & 0.24 & -33.87 & -62.24 & -29.44 \\
\hline 318.15 & 1.310 & 0.17 & -32.80 & & \\
\hline
\end{tabular}

\section{Phase behavior in aqueous/oil mixtures}

Focusing on EOR, salinity scans with both SAILs ([HOPro][DS] (13) and [HOPro][DBS] (14) were carried out. The first one, the SAIL with [DS] anion, formed in the presence of $n$-octane, with a WOR 1 and $2 \%$ wt surfactant, microemulsions type Winsor I up to $15 \% \mathrm{wt} \mathrm{NaCl}$ at $298.15 \mathrm{~K}$. When samples were tested at $323.15 \mathrm{~K}$ the same behavior was observed. So the SAIL seems to be too hydrophilic to be used alone for EOR applications.

However, with the [DBS] anion, the IL generated a transition from Winsor type I to Winsor type II microemulsions at the tested temperatures. Figure 7 shows photographs of salinity scans at 298.15 (top) and $348.15 \mathrm{~K}$ (bottom) for aqueous solutions of [HOPro][DBS] (14) equilibrated with equal volumes of $n$-octane, with an overall surfactant concentration of $2 \%$. At $298.15 \mathrm{~K}$, the separation of the phases in the Winsor type III region takes a long time. After one month, at $5 \%$ wt $\mathrm{NaCl}$, a middle phase microemulsion with really low solubilisation parameter was found ( 2). The behavior was similar at $323.15 \mathrm{~K}$. However, at $348.15 \mathrm{~K}$, the SAIL generated classical microemulsion phase behavior, Winsor I-III-II transition. Figure 8 shows solubilisation parameters for this temperature $\left(V_{o} V_{s}\right.$ and $V_{w} N_{s}$ ) as a function of salinity. An optimal salinity of $\sim 8.5 \%$ wt $\mathrm{NaCl}$ was found with a solubilisation parameter of $\sim 10$ for the middle phase microemulsion. Chung-Huh correlation (equation 8) was used to calculate IFT from the solubilisation parameters. ${ }^{[21]}$ where $\mathrm{C}=0.3, \sigma_{o}=V_{o} V_{s}$. According to this correlation, this microemulsion should produce ultralow IFT of $\sim 3 \cdot 10^{-3} \mathrm{mN} / \mathrm{m}$. So, the amino acid-based SAIL [HOPro][DBS] (14) is promising for EOR applications at high temperatures and salinity with probably low enough interfacial tensions to displace a substantial proportion of oil.

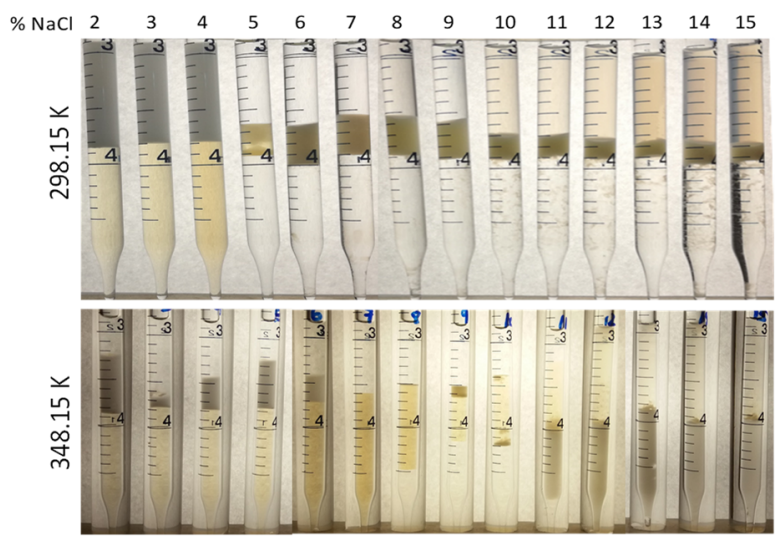

Figure 7. Salinity scans at 298.15 and $348.15 \mathrm{~K}$ for $2 \% \mathrm{wt}$ [HOPro][DBS] (14), WOR 1, $n$-octane, $\mathrm{NaCl}$ brine.

$$
\gamma_{m}=C /\left(\sigma_{o}\right)^{2}
$$




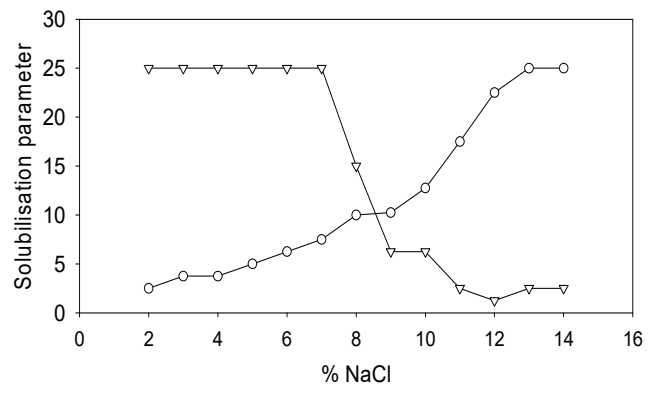

Figure 8. Solubilisation parameters $(\neg \vee-V w / V s,-O-V o / V s)$ from salinity scans at $348.15 \mathrm{~K}$ for $2 \% \mathrm{wt}$ [HOPro][DBS] (14), WOR 1, n-octane, $\mathrm{NaCl}$ brine.

\section{Conclusions}

Amino acid ILs share the promising advantages of ILs, and being derived from a biomolecular structure, they could be considered true green solvents. Some ILs obtained from amino acids by carboxylic acid esterification were presented to the scientific community as stable and highly biodegradable, and some applications were also suggested, most of them involving an aqueous environment. However, the studies carried out in this work on the stability of similar structures derived from proline esters, have shown that the ester group incorporated into the cation undergoes hydrolysis in the presence of water.

A new family of biodegradable amino acid derived ILs avoiding carboxylic acid esterification by its reduction to an alcohol is proposed in this work. Resulting ILs are not only thermally but also hydrolytically stable. Prolinolium cation [HOPro] was selected as cation and combined with anions able to confer a surface active character to the ILs: dodecylsulfate and dodecylbenzenesulfonate. The first SAIL, [HOPro][DS], showed the same problems as the traditional surfactant $\mathrm{Na}[\mathrm{DS}]$ regarding the hydrolysis of the anion. However, [HOPro][DBS] shown to be fully stable. Both SAILs form micelles in aqueous solutions and are more effective to reduce the surface tension of water than the traditional corresponding parents ( $\mathrm{Na}[\mathrm{DS}]$, $\mathrm{Na}[\mathrm{DBS}])$. However, the effectiveness of SAILs adsorption at the water-oil interface is lower. These Room Temperature lonic Liquids are recommended for applications taking advantage of its capacity of aggregation.

Both SAILs were tested for EOR applications. An optimal formulation, useful for reservoirs at high salinities and temperatures, was found with [HOPro][DBS]. An ultra-low interfacial water-oil of $\sim 3 \cdot 10^{-3} \mathrm{mN} / \mathrm{m}$ is expected. This low value is able to reduce the capillary forces that trap the oil in the pores of the rock pushing it out of the reservoir.

\section{Experimental Section}

The reagents and solvents were purchased from commercial suppliers and employed without further purification. The glass material employed in the synthetic reactions was dried in an oven at $333.15 \mathrm{~K}$ during $24 \mathrm{~h}$ before its use. The evolution of the reactions was monitored by thin layer chromatography (t.l.c.) employing silica-gel sheets (Merck, TLC Silica gel $60 \mathrm{~F} 254$ ) and $\mathrm{MeOH}: \mathrm{CH}_{2} \mathrm{Cl}_{2} 5 \%$ as eluent; t.l.c. plates were visualised by treatment with a solution of nynhidrine as revealing agent. ${ }^{1} \mathrm{H}$ and ${ }^{13} \mathrm{C}$ NMR spectra were recorded on a BRUKER ARX 4CO spectrometer at $400.1621\left({ }^{1} \mathrm{H}\right)$ and $100.6314\left({ }^{13} \mathrm{C}\right) \mathrm{MHz}$, respectively. $\mathrm{CDCl}_{3}$ (ACROS Organics, 99.6+ atom \% D) and $\mathrm{D}_{2} \mathrm{O}$ (ACROS Organics, 99.8+ atom \% D) were employed as deuterated solvents as received from the supplier. Chemical shifts are quoted in parts per million (ppm) relative to the signals corresponding to the residual non-deuterated solvents $\left(\mathrm{CDCl}_{3}: \delta \mathrm{H}\right.$ $=7.26 \mathrm{ppm}, \delta \mathrm{C}=77.16 \mathrm{ppm}, \mathrm{D}_{2} \mathrm{O}: \delta \mathrm{H}=4.79 \mathrm{ppm}$ ). Mass spectra were recorded on a BRUKER FTMS APEXIII mass spectrometer. A purity greater than $99 \mathrm{wt} \%$ is estimated for all the ILs synthesized in this study.

Differential scanning calorimetry (DSC) experiments were run in a TA Instruments Q2000 differential scanning calorimeter, with heating and cooling rates of $5 \mathrm{~K} \cdot \mathrm{min}^{-1}$. $\mathrm{N}_{2}$ (Praxair, $99.999 \%$ ) was used as sample purge gas with $50 \mathrm{~mL} / \mathrm{min}$ flow. Three cycles were carried out, being second and third cycle coincident. Thermal stability of the samples was measured in a TA Instruments Q500 thermogravimetric analysis (TGA) apparatus. Samples were initially heated $\left(5 \mathrm{~K} \cdot \mathrm{min}^{-1}\right)$ from room temperature to $348 \mathrm{~K}$, then being held isothermally at this temperature for $30 \mathrm{~min}$ to help removing water and other volatile compounds that might be present. After that isothermal step, the samples were further heated, at a rate of $5 \mathrm{~K} \cdot \mathrm{min}^{-1}$, up to $773 \mathrm{~K}$, under a constant nitrogen gas flow of $60 \mathrm{~mL} / \mathrm{min}$. DSC and TGA thermograms were evaluated using the Universal Analysis 2000 software (Version 4.5.0.5A) by TA Instruments.

Surface tension measurements were carried out using a Krüss K11 tensiometer based in the Wilhelmy plate method. All measurements were carried out at $298.15 \mathrm{~K}$ using a Julabo F12 cryogenic thermostat for temperature control. Electric conductivity was measured using a Basis 30 Crison electric conductivimeter connected to a thermostatic bath (Julabo F12-EH). Measurements were carried out at four different temperatures ranging from 288.15 to $318.15 \mathrm{~K}$ at $10 \mathrm{~K}$ interval. To check micelles size, some samples (surfactant solutions with concentration ca. 20 times above the $\mathrm{cmc}$ ) were analyzed at room temperature via a Malvern Zetasizer Nano ZS apparatus to perform Dynamic Light Scattering measurements. The estimated uncertainty in aggregates diameter is 0.2 $\mathrm{nm}$. In the case of Transmission Electron Microscopy tests, samples were prepared by putting a drop of surfactant solution (with concentration ca. 20 times above the $\mathrm{cmc}$ ) on the carbon-coated Nickel grid (400 mesh). Samples were imaged under a JEOL JEM1010 electron microscope at a working voltage of $100 \mathrm{kV}$.

Salinity scans were carried out in encased glass pipettes adding $1 \mathrm{~cm}^{3}$ of aqueous surfactant solution ( $4 \%$ wt SAIL) and $1 \mathrm{~cm}^{3}$ of $n$-octane as model oil. Tests at room temperature were carried out mixing the samples approximately $24 \mathrm{~h}$ using a rotary mixer and letting them to equilibrate until the phases volume remained constant. The same procedure was used with tests at higher temperature but a Julabo F12-EH was used for temperature control. Solubilization parameters and optimal salinity were calculated from the equilibrated phase volumes. Further details of the experimental set-up can be found in [14]. 


\section{Acknowledgements}

A. Soto acknowledges the Ministry of Economy and Competitiveness (Spain) for financial support throughout project CTQ2015-68496-P (including European Regional Development Fund advanced funding). E. Tojo thank the Xunta de Galicia (ED431D 2017/06) for their financial support as well as the research support services of the University of Vigo (CACTI) for the NMR and MS divisions work.

Keywords: Ionic Liquids - amino acids • surfactants • prolinolium • EOR

[1] A. Romero, A. Santos, J. Tojo, A. Rodríguez, J. Hazar. Mat. 2008, 151, 268-273.

[2] M. J. Earle, K. R. Seddon. Pure Appl. Chem. 2000, 72, 1391-1398.

[3] Y. Deng, S. Morrissey, N. Gathergood, A. M. Delort, P. Husson, M. F. Costa-Gomes, ChemSusChem 2010, 3, 377-385.

[4] K. Fukumoto, M. Yoshizawa, H. Ohno, J. Am. Chem. Soc. 2005, 127 (8), 2398-2399; G.H. Tao, L. He, W. S. Liu, L. Xu, W. Xiong, T. Wang, Y. Kou, Green Chem. 2006, 8, 639-646; H. Ohno, K. Fukumoto, Acc. Chem. Res. 2007, 40, 1122-1129; S. Kirchhecker, D. Esposito, Curr Opin. Green Sustainable Chem. 2016, 2, 28-33.

[5] D. S. Firaha, B. Kirchner, ChemSusChem 2016, 13, 1591-1599.

[6] K. Ohira, K. Yoshida, S. Hayase, T. Itoh, Chem. Letters 2012, 41, 987989.

[7] Y. Hamada, K. Yoshida, R. Asai, S. Hayase, T. Nokami, S. Izumib, T. Itoh, Green Chem. 2013,15, 1863-1868.

[8] L. Wu, X. Lu, H. Zhang, J. Chen, ChemSusChem 2012, 5,1918-1925.

[9] V. Fábos, D. Lantos, A. Bodor, A.M. Bálint, L . T. Mika, O. E. Sielcken, A. Cuiper, I. T. Horváth. ChemSusChem 2009,1,189-192.

[10] I. R. Collins, M. J. Earle, S. P. Exton, N. V. Plechkova, K. R. Seddon, PCT Int. Appl. 2006, WO 2006111712 A2.

[11] M. Blesic, A. Lopes, E. Melo, Z. Petrovski, N. V. Plechkova, J. N. Canongia Lopes, K. Seddon, L. P. N. Rebelo, J. Phys. Chem. B 2008, 112, 8645-8650

[12] T. J. Trivedi, K. S. Rao, T. Singh, S. K. Mandal, N. Sutradhar, A. B. Panda, A. Kumar, ChemSusChem 2011, 4, 604-608.

[13] A. Bera, H. Belhaj, J. Mol. Liq. 2016, 224, 177-188.

[14] I. Rodriguez-Escontrela, M. C. Puerto, C. A. Miller, A. Soto, J. Colloid. Interf. Sci. 2017, 504, 404-416.

[15] L. Dong, L. He, G.H. Tao, M. Huang, C. Hu, J. Chem. Eng. Data 2013, 58, 1176-1185

[16] K. S. Rao, P. S. Gehlot, H. Gupta, M. Grechsler, A. Kumar, J. Phys. Chem. B 2015, 119, 4263-4274.

[17] S. Y. Lin, Y. Y. Lin, E. M. Chen, C. T. Hsu, C.-C. Kwan, Langmuir 1999, 15, 4370-4376.

[18] K. S. Rao, T. Singh, T. J. Trivedi, A. Kumar, J. Phys. Chem. B 2011, 115, 13847-13853.

[19] M. J. Rosen in Surfactants and Interfacial Phenomena, John Wiley \& Sons, New York, 2004

[20] S. K. Hait, P. R. Majhi, A. Blume, S. P. Moulik, J. Phys. Chem. B 2003, 107, 3650-3658.

[21] C. Huh, J. Colloid Inter. Sci. 1979, 71, 408-426. 